\title{
Le Voyage en Orient de Chateaubriand, Actes du colloque de l'ENS Ulm sous la dir. de Jean-Claude Berchet
}

\section{Olivier Catel}

\section{(2) OpenEdition}

\section{Journals}

Édition électronique

URL : http://journals.openedition.org/studifrancesi/9581

DOI : 10.4000/studifrancesi.9581

ISSN : 2421-5856

Éditeur

Rosenberg \& Sellier

\section{Édition imprimée}

Date de publication : 1 décembre 2007

Pagination : 672-673

ISSN : 0039-2944

\section{Référence électronique}

Olivier Catel, « Le Voyage en Orient de Chateaubriand, Actes du colloque de I'ENS UIm sous la dir. de Jean-Claude Berchet », Studi Francesi [En ligne], 153 (LI | III) | 2007, mis en ligne le 30 novembre 2015, consulté le 08 janvier 2021. URL : http://journals.openedition.org/studifrancesi/9581 ; DOI : https:// doi.org/10.4000/studifrancesi.9581

Ce document a été généré automatiquement le 8 janvier 2021.

\section{c) $(9 \odot$}

Studi Francesi è distribuita con Licenza Creative Commons Attribuzione - Non commerciale - Non opere derivate 4.0 Internazionale. 


\title{
Le Voyage en Orient de Chateaubriand, Actes du colloque de l'ENS Ulm sous la dir. de Jean-Claude Berchet
}

\author{
Olivier Catel
}

\section{RÉFÉRENCE}

Le Voyage en Orient de Chateaubriand, Actes du colloque de l'ENS Ulm sous la dir. de JeanClaude BERCHET, Paris, Éditions Manucius, 2006, pp. 347.

1 Ce volume réunit les actes du colloque organisé par la Société Chateaubriand 19 et 20 octobre 2006 à l'occasion de la mise au programme de l'agrégation de lettres 2007 de l'Itinéraire de Paris à Jérusalem. Il est organisé autour d'aspects historiques, politiques et autobiographiques, mais aussi analyse l'héritage littéraire dont se sert Chateaubriand pour consumer son écriture viatique personnelle.

2 Jean-Claude BERCHET (pp. 11-19) rappelle qu'à la fin de cet ouvrage l'auteur renonce à la Poésie pour se consacrer à l'écriture de l'Histoire et fait remarquer que, si Chateaubriand n'aborde pas de front les problèmes politiques, il dénonce cependant le despotisme oriental et prépare un éloge de la liberté qu'il oppose bientôt au despotisme napoléonien. Jacques-Alain de séDouy (pp. 23-29) rappelle la politique de Napoléon pris entre son rêve oriental et son réalisme politique. Jean-Paul CLÉMENT (pp. 31-51) montre que la Grèce revient à la mode et que Chateaubriand ne rencontre pas les élites. Gilles VEINSTEIN (pp. 53-61) étudie comment Chateaubriand dénonce un système politique mauvais qui a l'islam et le despotisme oriental pour fondements.

Alain GUYOT (pp. 65-87) compare trois versions du voyage de l'auteur et dégage comment Chateaubriand recherche une plus grande tension dramatique, l'expression de l'émotion juste, tente de donner à son récit de voyage une unité de ton pour finalement construire la dimension autobiographique du texte. Guy BERGER et Bernard DEGOUT (pp. 89-116), qui étudient les réactions de la presse, démontrent que les articles 
parus dans le «Mercure» en 1807 concernant le voyage de l'auteur ne sont que très peu censurés, le régime ne voyant dans ces récits rien qui puisse le mettre en danger. Bernard DEGOUT (pp. 117-127) prouve que la longue maturation des Mémoires a commencé dès le voyage en Orient sans que Chateaubriand, sur le moment, s'en rende compte.

Philippe ANTOINE (pp. 131-141) esquisse les nombreux rapprochements possibles entre Le Voyage du jeune Anacharsis et l'Itinéraire. Élisa GREGORI (pp. 143-151) présente un Chateaubriand archéologue pour lequel le fragment et l'objet priment sur le monument, les mines et les citations devenant des restes du passé qui remplissent symboliquement le même rôle. Marika PIVA (pp. 153-173), quant à elle, insiste sur les différents intertextes présents dans l'Itinéraire: la Bible est convoquée comme Homère, la Jérusalem délivrée comme Tite-Live. Philippe BERTHIER (pp. 175-185) souligne que si les noms se perdent et deviennent lettre morte dans ce monde sans nom qu'est l'Amérique, ceux du monde ancien n'attendent qu'une résurrection poétique. Patrizio Tucci (pp. 189-210) inscrit Chateaubriand dans la grande tradition du pèlerinage chrétien, un iter ritualisé par un protocole descriptif, tout empreint de la crainte et du respect devant la Terre Sainte. Jean-Marie Roulin (pp. 211-225) étudie les nombreuses références épiques dans ce récit de voyage: Chateaubriand enchante la mémoire historique, préfère le possible et l'universel de l'épopée au ponctuel et à l'accompli de l'Histoire.

5 Fabio VASARRI (pp. 227-244) explore le rire dans l'Itinéraire, ouvrage au ton dégagé, où s'expriment l'euphorie du dépaysement et la liberté de l'auteur face aux genres. Jacques Dupont (pp. 247-264) met en relief l'ébriété de la citation et la folie de l'exhaustivité qui s'emparent du narrateur. Jean-Claude BONNET (pp. 265-288) se penche sur la place du thème du repas qui scande l'errance du voyageur, plaisirs de la table qui lui révèlent l'hospitalité turque, consulaire, apostolique et familiale. Jean-Marie Roulin (pp. 291-307) explique que Chateaubriand ne reconnait plus la France du début de xix ${ }^{\mathrm{e}}$ siècle et se lance alors dans une entreprise de refondation où la patrie devient, tour à tour, une qualité de l'esprit, marquée de catholicisme, religion de ses pères, ou encore une nation troubadour. Arnaud BERNADET (pp. 309-323) s'intéresse aux rapports entre la langue et l'altérité: si le «moi» met en scène le nom propre du locuteur, le «je» insiste, quant à lui, sur l'individuation, le sujet du langage; l'exil en pays barbare révèle à Chateaubriand sa propre étrangeté, c'est-à-dire l'absence et la dépossession de soi. Sarga MOUSSA (pp. 325-339), analysant les catégories de la différence, montre que l'idée de «race» est une catégorie peu opératoire dans l'Itinéraire et que Chateaubriand préfère opposer l'islam au christianisme, la sauvagerie à la barbarie ou le despotisme à l'esclavage.

Ces communications donnent l'image d'un récit souvent déroutant, toujours inattendu, qui signe l'émergence d'un «je» occidental et autobiographique dans le récit viatique. 